Research Article

\title{
Evaluation of Comprehensive Ability of Accounting Applied Talents Based on GFAHP-Cloud Model
}

\author{
Qingyang Zhang $(\mathbb{D}$ \\ Business \& Tourism Institute, Hangzhou Vocational and Technical College, Hangzhou, Zhejiang 310018, China \\ Correspondence should be addressed to Qingyang Zhang; 2007010025@hzvtc.edu.cn
}

Received 17 November 2021; Revised 7 December 2021; Accepted 13 December 2021; Published 30 December 2021

Academic Editor: Wen-Tsao Pan

Copyright ( 2021 Qingyang Zhang. This is an open access article distributed under the Creative Commons Attribution License, which permits unrestricted use, distribution, and reproduction in any medium, provided the original work is properly cited.

Through the objective and fair evaluation of the comprehensive ability of accounting talents cultivated in colleges and universities, on the one hand, it is beneficial to provide direction for cultivating accounting applied talents in colleges and universities, and on the other hand, it can also provide reference for enterprises to select talents. Firstly, this study constructs an evaluation index system for the comprehensive ability of accounting applied talents and selects 15 indicators from three aspects of knowledge level, ability level, and moral level. Secondly, the group fuzzy analytic hierarchy process is used to determine the index weight. Finally, a fuzzy comprehensive evaluation model based on the cloud model is constructed and tested in practice. This study hopes to make an objective and fair evaluation for accounting talents by quantitatively evaluating the comprehensive ability of accounting applied talents.

\section{Introduction}

With the transformation of world economy from industrial economy to knowledge economy and the rapid development of economy and society in China, accounting applied talents play an important role in economic and social development as practical and applied human resources $[1,2]$. Therefore, the ability and quality of accounting applied talents are facing various new challenges. The evaluation of accounting applied talents is the basic link of the overall training, development, and use of accounting applied talents, which play a connecting role [3]. So, it is of great theoretical and practical significance to evaluate the comprehensive ability of accounting applied talents cultivated in colleges and universities objectively and fairly.

First, it is beneficial for schools to formulate training plans $[4,5]$. The teachers can objectively find the advantages and disadvantages of students through reasonable comprehensive evaluation. It can not only give full play to the advantages of students, but also make up for the disadvantages through targeted teaching, so that each student can enjoy the learning process and truly learn knowledge. Second, it is beneficial for enterprises to select and recruit talents. If there is a complete and reasonable evaluation system of accounting applied talents, enterprises can choose some position interns according to the evaluation results. Interns recruited in this way are more in line with the requirements of enterprise work and the employment direction of students [6-8]. This directional selection of talents is based on the needs of enterprises and students to work matching, which can not only reduce the cost of human resources, but also save students' time, so as to achieve a winwin goal of job seekers and interviewers [9]. Third, it is conducive to the implementation of people-oriented development concept. The people-oriented development concept mainly means full respect for the wishes of students and teachers in colleges and universities [10,11]. It can fully consider the wishes of students and teachers through the implementation of objective and fair university talent evaluation mechanism and truly implement the peopleoriented development concept.

However, there are still many deficiencies in the comprehensive ability evaluation of accounting applied talents. On the one hand, there is a lack of an evaluation system for the comprehensive ability of accounting applied talents, and the existing evaluation index system cannot fully reflect the 
characteristics of accounting applied talents [12]. On the other hand, the current society is mainly aimed at the evaluation of accounting professional ability, which cannot scientifically and comprehensively evaluate the comprehensive ability of accounting talents. Moreover, although the current research results have promoted the reform of accounting education and the improvement of the quality of accounting talents to varying degrees, the orientation of the training objectives of accounting talents is not clear enough, and there is no evaluation model for the comprehensive ability of accounting talents from a comprehensive perspective. Therefore, it is necessary to study the comprehensive ability evaluation method of accounting applied talents.

By analyzing the existing research results and evaluation methods, we found that previous studies mostly used qualitative research methods, but lacked quantitative assessment and evaluation. Therefore, the main contribution of this study has two aspects. On the one hand, this study constructs the comprehensive ability evaluation index system of accounting applied talents from three aspects of knowledge level, ability level, and moral level. On the other hand, this study puts forward a kind of fuzzy comprehensive evaluation method, which uses group fuzzy analytic hierarchy process and cloud model to evaluate the comprehensive ability of accounting applied talents. Its advantage is that it can significantly reduce the interference of subjective factors to a certain extent and quantitatively analyze nonquantitative factors. In addition, the determination and calculation of index weights at all levels are also more scientific. This method has higher accuracy than the traditional fuzzy comprehensive evaluation method, and the results are closer to the actual situation.

This study is divided into five parts. The first part describes the research background and significance. The second part summarizes the relevant literature research. The third part constructs the comprehensive ability evaluation index system of accounting applied talents from three aspects of knowledge level, ability level, and moral level. The fourth part describes the modeling process of group fuzzy analytic hierarchy process and cloud model fuzzy comprehensive evaluation method. Finally, taking "class A" as an example, it is found that the method proposed in this study can more accurately evaluate the comprehensive ability of accounting applied talents.

\section{Related Work}

To improve the comprehensive quality and ability of accounting practitioners, researchers realize that the implementation of accounting talent evaluation system is very important, which is helpful to improve the service quality of accounting industry and promote its steady development in the era of big data. At present, the research on accounting talents mainly includes training mode and ability evaluation. For example, Liu [13] proposed a talent innovation training model suitable for China after comparing it with European and American countries, including four aspects: scientific research, teaching methods, school-enterprise cooperation, and innovation projects. Finally, the applicability of this model was proved by taking the accounting profession as an example. After analyzing the problems existing in the process of cultivating accounting talents, Song [14] put forward the innovation of cultivating accounting talents from the aspects of teaching content and environment, teachers, and teaching evaluation system, so that accountants can better adapt to the changes brought by artificial intelligence. With the advent of the era of big data, Zhang [15] believed that accounting personnel training mode should keep pace with the times. By analyzing the problems existing in the traditional mode of accounting teaching, this study put forward a digital teaching effect monitoring mode, emphasizing the cultivation of students' practical ability. Other scholars analyze and evaluate the comprehensive ability of accountants from different angles. For example, Zhu et al. [16] constructed an evaluation index system from four aspects of learning ability, professional level, management ability, and self-discipline and then used the questionnaire survey method to study the competency of accounting applied talents. The results showed that the comprehensive ability of accounting applied talents in China is at a good level.

There are many evaluation methods about talent ability. For example, Lan [17] constructed the evaluation index system of innovative ability of talents from four aspects: learning ability, innovative thinking ability, observation ability, and self-confidence and then evaluated it by matterelement extension method. The results showed that this method can reflect the strength of talent innovation ability from different perspectives. Guo and Yang [18] constructed the evaluation index system of urban talent aggregation ability from the perspective of urban economic development level, construction and environmental conditions, education and medical and health services, living standards, and career development platform and then used principal component analysis to conduct empirical research. He et al. [19] constructed an evaluation index system for the teaching ability of university scientific research talents according to the requirements and actual situation of cultivating students in colleges and universities and then used BP neural network and fuzzy mathematics theory to evaluate it. Through empirical research, it is found that this method can be applied to the actual evaluation process and can improve the evaluation efficiency to a certain extent. The same is to evaluate the teaching ability, and Gao [20] innovatively introduced data mining into evaluation and found that the method can more truly reflect the teaching ability of teachers through empirical research.

\section{Design of Comprehensive Ability Evaluation Index System for Accounting Applied Talents}

3.1. Principle of Design. Since the selection of indicators is related to whether the evaluation results are comprehensive and accurate, some principles should be followed in the construction of the index system, so as to ensure that the final evaluation results are feasible. By searching and reading relevant literature, this study finds that the selection of fair 
evaluation index of comprehensive ability of talent training should have the following principles:

(1) Comprehensive principle: we need to take into account all aspects related to the comprehensive ability of personnel training, so we should conduct a comprehensive assessment from the aspects of morality, ability, physical quality, and mental health of college students majoring in accounting.

(2) Typical principle: we need to ensure that each selected evaluation index has a certain typical representativeness, on the basis of simply indicating the inherent meaning of the evaluation object. We should reflect the performance of college accounting students in different aspects as accurately as possible.

(3) Operative principle: we need to ensure that there is a correlation between the selected indicators, so the results will be more accurate when the experts score the importance of the two indicators, so that the final calculated index weight is more convincing.

3.2. Index System Establishment. This study summarizes the literature on the comprehensive ability evaluation of accounting personnel training and combines the opinions and suggestions of experts and professors to fully understand the comprehensive ability evaluation system of accounting applied talents. Then, according to the basic idea of analytic hierarchy process, the relationship between the internal factors of the system is analyzed, and the comprehensive ability evaluation index system of accounting applied talents is established as shown in Figure 1 .

\section{GFAHP-Cloud Model for Comprehensive Ability Evaluation of Accounting Applied Talents}

4.1. GFAHP for Criteria Weight Determination. The index system established in this study has a clear hierarchical structure, so the analytic hierarchy process (AHP) is selected as the basic method for the comprehensive ability evaluation of accounting applied talents. However, the traditional AHP method has two main problems in determining the weight. On the one hand, in the case of many indicators, complex index system, and wide range of knowledge involved, individual decision-makers are limited by personal ability, knowledge, and experience, which can easily lead to deviation between the weight judgment results and the actual situation. On the other hand, when experts use the 1-9 scale method to score, it is easy to appear difficult to express fuzzy cognition $[21,22]$.

Therefore, this study selects group fuzzy analytic hierarchy process (GFAHP) to determine the index weight. On the one hand, the triangular fuzzy number is introduced to improve the analytic hierarchy process so that each index has a fuzzy evaluation interval. This interval can be used to compare the relative importance of the elements, which may leave a margin for the uncertainty of the experts. The existence of this interval reflects the influence of the uncertainty of the relative importance of experts among elements on the evaluation results to a certain extent. On the other hand, when this method gives the judgment matrix, it is not given by an expert but by a group of experts to give their individual judgment matrix and then assembles each judgment matrix to form a group judgment matrix. The aggregation of individual judgment matrix needs to introduce expert opinion consistency weight and expert authority weight. The expert consistency weight is aggregated by clustering analysis method, and the expert authority weight is aggregated by group decision-making. This takes into account both the concentration of expert opinions and the authority of experts, so as to avoid inaccurate decisionmaking results due to the subjective preferences of an expert [23].

4.1.1. Triangular Fuzzy Number. Let a fuzzy be set as $\widetilde{X}$ on the domain $\mathrm{V}$ if

(1) The membership function of $\widetilde{X}$ can be expressed as $\mu_{\tilde{x}}(x): V \longrightarrow[0,1]$

$$
\mu_{\tilde{x}}(x)= \begin{cases}0, & x<a, \\ \frac{x-a}{b-a}, & a \leq x \leq b, \\ \frac{c-x}{c-b}, & b \leq x \leq c, \\ 0, & x>c .\end{cases}
$$

In the formula, $a \leq b \leq c, a, b, c$ denote the lower bound, intermediate value, and upper bound of $\tilde{X}$, respectively.

(1) Existence $x_{0} \in R$ makes $\mu_{\tilde{X}}\left(x_{0}\right)=1$

(2) For any $\lambda \in(0,1), \quad \widetilde{X}_{\lambda}=\left\{x \mid \mu_{X}(x) \geq \lambda\right\} \quad$ is a convex set

$\tilde{X}$ is called triangular fuzzy number and can be denoted as $\tilde{X}=(a, b, c)$.

Assuming that $\tilde{X} 1=\left(a_{1}, b_{1}, c_{1}\right)$ and $\tilde{X}_{2}=\left(a_{2}, b_{2}, c_{2}\right)$ are two triangular fuzzy numbers, the possibility degree of $X_{1} \geq X_{2}$ is defined as follows:

$$
\left\{V\left(X_{1} \geq X_{2}\right)=\left\{\begin{array}{ll}
1, & b_{1} \geq b_{2}, \\
\frac{a_{2}-c_{1}}{\left(b_{1}-c_{1}\right)-\left(b_{2}-a_{2}\right)}, & b_{1} \leq b_{2}, c_{1} \geq a_{2}, \\
0, & \text { otherwise. }
\end{array}\right\}\right.
$$

The possibility degree of $X \geq X_{1}, X_{2}, \ldots, X_{n}$ is defined as follows:

$V\left(X \geq X_{1}, X_{2}, \ldots, X_{n}\right)=\min V\left(X \geq X_{i}\right) i=1,2, \ldots, n$. 


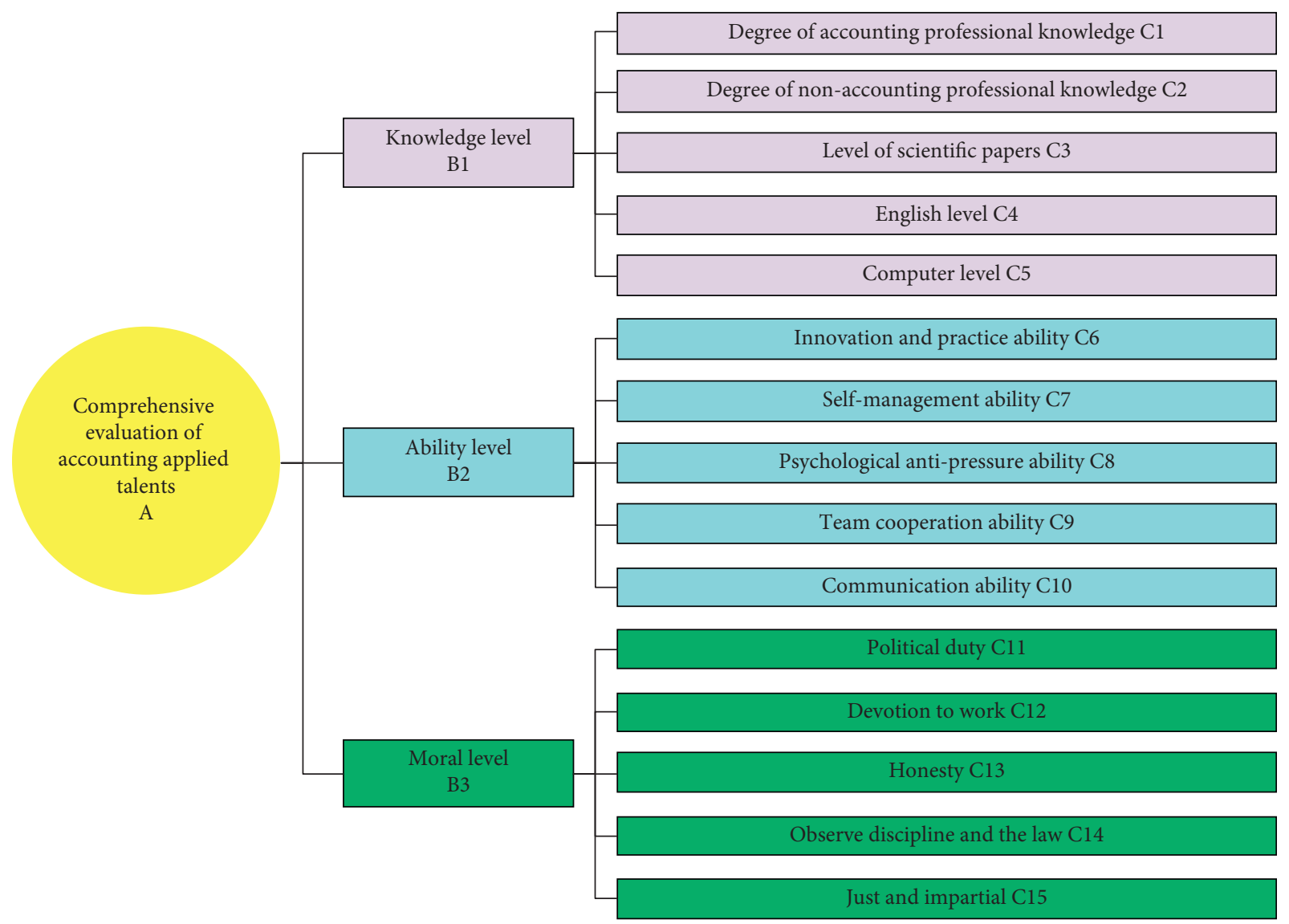

Figure 1: Evaluation index system of comprehensive ability of accounting applied talents.

\subsubsection{GFAHP}

\section{(1) Construct Fuzzy Judgment Matrix}

(1) Define the mapping of comment sets and fuzzy numbers. Table 1 shows the comment set and its corresponding fuzzy numbers.

(2) Decision-makers provide judgment matrices separately. The experts score according to the scale and label in Table 1. The importance judgment matrix of indicators is as follows:

$$
\widetilde{X}^{k}=\left(\begin{array}{cccc}
a_{11} & a_{12} & \ldots & a_{1 n} \\
a_{21} & a_{22} & \ldots & a_{2 n} \\
\ldots & \ldots & \ldots & \ldots \\
a_{n 1} & a_{n 2} & a_{11} & a_{n n}
\end{array}\right) .
$$

In the formula, $a_{i j}$ is the comment set in Table 1, indicating the importance of the index $i$ relative to the index $j$ under the same criterion layer, and $k$ represents the $\mathrm{k}^{\text {th }}$ expert.

(3) Weight average of decision-makers. The formula for calculating the weighted average of expert scoring is as follows:
Table 1: Mapping between comment set and fuzzy number.

\begin{tabular}{lcccc}
\hline Evaluation scale & Label & $\begin{array}{c}\text { Fuzzy } \\
\text { number }\end{array}$ & Label & $\begin{array}{c}\text { Fuzzy } \\
\text { number }\end{array}$ \\
\hline Completely equal & $\mathrm{P}$ & $(1,1,1)$ & $\mathrm{DP}$ & $(1,1,1)$ \\
Equal importance & $\mathrm{C}$ & $(1 / 2,1,3 / 2)$ & $\mathrm{DC}$ & $(2 / 3,1,2)$ \\
A little important & $\mathrm{L}$ & $(1,3 / 2,2)$ & $\mathrm{DL}$ & $(1 / 2,2 / 3,1)$ \\
General important & $\mathrm{G}$ & $(3 / 2,2,5 / 2)$ & $\mathrm{DG}$ & $(2 / 5,1 / 2,2 / 3)$ \\
Very important & $\mathrm{V}$ & $(2,5 / 2,3)$ & $\mathrm{DV}$ & $(1 / 3,2 / 5,1 / 2)$ \\
Extremely & $\mathrm{E}$ & $(5 / 2,3,7 / 2)$ & $\mathrm{DE}$ & $(2 / 7,1 / 3,2 / 5)$ \\
important & & & &
\end{tabular}

Note. P and DP represent the opposite important relationship.

$a_{i j}=\left(\sum_{k=1}^{n} \frac{a_{k}}{n}, \sum_{k=1}^{n} \frac{b_{k}}{n}, \sum_{k=1}^{n} \frac{c_{k}}{n}\right), \quad k=1,2, \ldots, n$

In the formula, $l k, m k, u k$ represent the expert to each index score, and $n$ represents the number of experts.

(2) Consistency Test of Judgment Matrix. Firstly, the triangular fuzzy judgment matrix is transformed into the consistency judgment matrix by the defuzzification method. In this study, formula (6) is used for defuzzification. 


$$
\operatorname{Deff}(\tilde{M})=\frac{a+4 b+c}{6} .
$$

Secondly, the matrix consistency index is calculated by formula (7), where $\lambda \max$ is the largest eigenvalue in comparison matrix, and $m$ is the order of the matrix.

$$
C I=\frac{\lambda_{\max }-m}{m-1}
$$

Finally, the matrix consistency ratio is calculated by formula (8). The value of RI is shown in Table 2.

$$
C R=\frac{C I}{R I}
$$

If $C R \leq 0.1$, it is considered to pass the consistency test; otherwise, the decision-maker needs to readjust the judgment matrix.

(3) Calculate Weights. Firstly, according to formula (9), the comprehensive fuzzy weight value of the factor $i$ in the $k$ layer of the criterion layer is calculated.

$$
\widetilde{w}_{i}^{K}=\sum_{j=1}^{n} a_{i j}^{K} \times\left(\sum_{i=1}^{n} \sum_{j=1}^{n} a_{i j}^{K}\right)^{-1}, \quad i=1,2, \ldots, n .
$$

Then, formula (10) is used to defuzzify the comprehensive fuzzy weight value and normalize it to calculate the weight value of each factor in the $k$ layer.

$w_{i}^{K}=V\left(\widetilde{w}_{i}^{K} \geq \widetilde{w}_{1}^{K}, \ldots, \widetilde{w}_{i-1}^{K}, \widetilde{w}_{i+1}^{K}, \ldots, \widetilde{w}_{n}^{K}\right), \quad i=1,2, \ldots, n$.

Finally, according to formula (11), the weight value of factor $m$ relative to the total goal is obtained, where $W_{i}$ represents the weight value of element $i ; W_{i j}$ represents the weight value of the sub-element $j$ of element $i$ to element $i$; and wjm represents the weight value of the child element $k$ of element $j$ to element $j$.

$$
W_{m}=W_{i} W_{i j} W_{j m} \text {. }
$$

In summary, the general idea of the group fuzzy analytic hierarchy process model is shown in Figure 2.

4.2. Cloud Model. The cloud model theory has the advantages of describing the randomness and uncertainty of fuzzy evaluation system and can transform qualitative concepts and quantitative values [24]. Based on the advantages of cloud model theory, this study combines cloud theory and fuzzy comprehensive evaluation model to improve the accuracy of comprehensive ability evaluation of accounting applied talents.

4.2.1. Basic Theory of Cloud Model. The basic theory of cloud is as follows: assuming that $U$ is a specific range of numerical changes, $T$ is a qualitative concept with a certain correspondence with $U$, and the membership degree $C T(x)$ of the element $x(x \in X)$ to the concept represented by $T$ is a oneto-many probability distribution, then the distribution of membership degree constitutes a mapping from the universe $U$ to the interval $[0,1]$, and the macro is the cloud. The cloud droplets are the basic unit of clouds. A certain number of
TABLE 2: RI values under different orders.

\begin{tabular}{lcccccccccc}
\hline Order & 1 & 2 & 3 & 4 & 5 & 6 & 7 & 8 & 9 & 10 \\
\hline RI & 0 & 0 & 0.58 & 0.9 & 1.12 & 1.24 & 1.32 & 1.41 & 1.45 & 1.49 \\
\hline
\end{tabular}

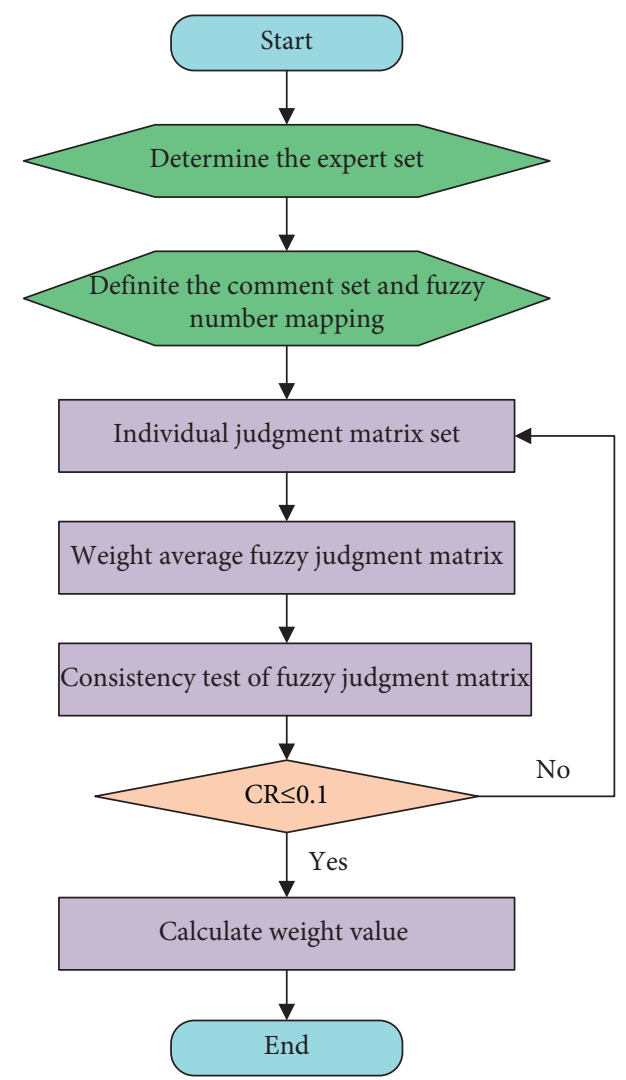

FIGURE 2: General idea of GFAHP model.

cloud droplets quantify the characteristics of qualitative concepts through their 3 digital features [25]. These three numerical characteristics are expected value, entropy, and hyper-entropy respectively, as shown in Figure 3.

Ex represents the center value of the concept in the domain, which is the position of the macroscopic peak of the cloud. Taking Figure 3 as an example, the expected value is 50 , indicating that the cloud droplets at 50 in the numerical domain have the largest membership degree, and the sample points corresponding to the cloud droplets are the most representative. En is the measurement of conceptual ambiguity, which reflects the bilateral boundary of qualitative concepts in the domain in a quantitative form and reflects the fuzziness of qualitative concepts. He is a measure of entropy randomness, reflecting the uncertainty of samples. The small hyper-entropy indicates that the uncertainty close to or away from the corresponding concept center is relatively small, reflecting the internal correlation between fuzziness and randomness. The concept of cloud is not a definite membership curve, but a qualitative concept represented by it. The cloud model integrates fuzziness and randomness through the above three digital features, and each cloud droplet represents a mapping of qualitative concepts in the quantitative domain. 


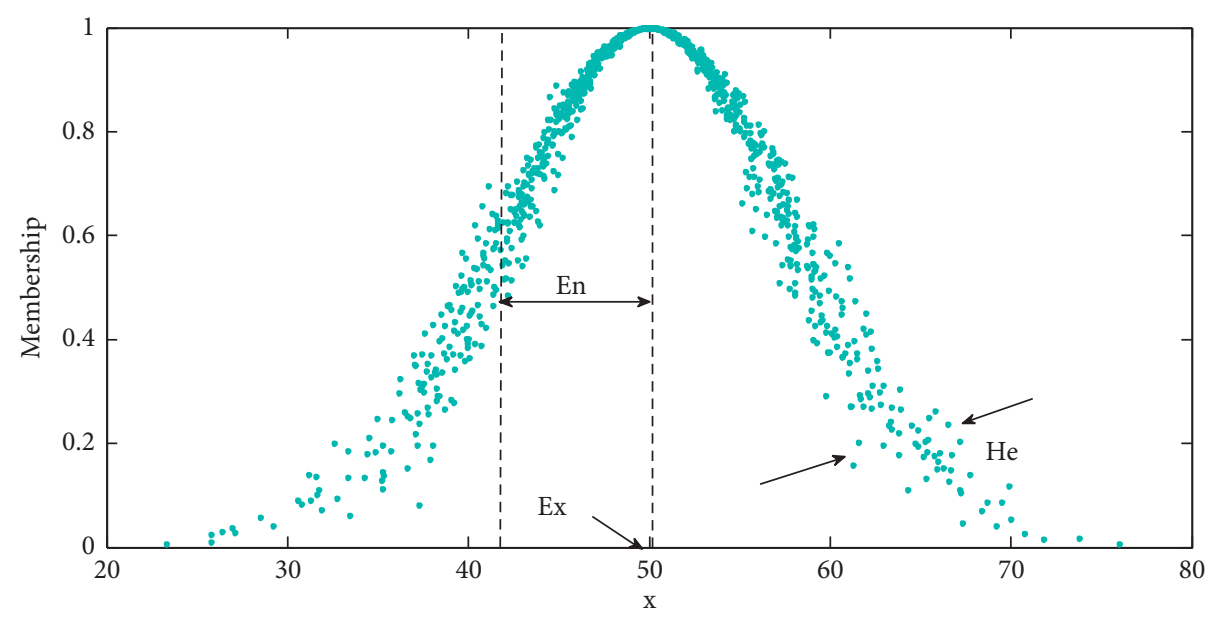

Figure 3: Digital feature diagram of cloud.

\subsubsection{Cloud Model Process}

(1) Because the corresponding evaluation values of different grades have bilateral value ranges, using cloud model to approximate the evaluation value can avoid the randomness and fuzziness ignored by previous numerical values and can form a more intuitive evaluation standard cloud. The calculation formula is as follows [26]:

$$
\begin{aligned}
& E x=\frac{C_{\max }+C_{\min }}{2}, \\
& E n=\frac{C_{\max }-C_{\min }}{6}, \\
& H e=k .
\end{aligned}
$$

(2) Because most of the variables in the evaluation index system are expressed in the way of language description, it is difficult to quantify by certain numerical value and only through experienced experts to score the qualitative description. After each expert gives the score of each indicator, the group decision cloud is calculated according to the following formulas:

$$
\begin{aligned}
& E x=\frac{\sum_{i=1}^{n} x_{i}}{n}, \\
& E n=\sqrt{\frac{\pi}{2} \times \frac{1}{n} \sum_{i=1}^{n}|x i-E x|,} \\
& H e=\sqrt{\frac{\sum_{i=1}^{n}\left(x_{i}-E x\right)^{2}}{n-1}-E n^{2} .}
\end{aligned}
$$

(3) After determining the standard cloud and weight coefficient, it is necessary to evaluate the comprehensive ability of accounting applied talents. The comprehensive evaluation results can be obtained by substituting the weight coefficient into the following formulas to calculate the cloud digital characteristics:

$$
\begin{aligned}
& E x=\sum_{i=1}^{n} E x_{i} \cdot \lambda_{i}, \\
& E n=\sqrt{\sum_{i=1}^{n} E n_{i}^{2} \cdot \lambda_{i},} \\
& H e=\sum_{i=1}^{n} H e_{i} \cdot \lambda_{i} .
\end{aligned}
$$

In summary, the cloud model fuzzy comprehensive evaluation method process is shown in Figure 4.

\section{Example Analysis}

5.1. Weight Calculation. This study adopts group fuzzy analytic hierarchy process to determine index weight. First of all, three experts are invited to score according to the importance of indicators. The three experts give the importance judgment matrix of each indicator layer, as shown in Appendix A. Then, the weighted average fuzzy judgment matrix and the maximum eigenvalues and eigenvectors of the matrix are calculated. After normalizing the feature vector, the index weight of the criterion layer is calculated, and finally, the final weight of each index can be obtained according to formula (11). The final results of the index weights are shown in Table 3 and Figure 5. Finally, the consistency of each judgment matrix is tested. If all of them pass one-time test, the index weight results are effective. According to the following results, it can be seen that the 


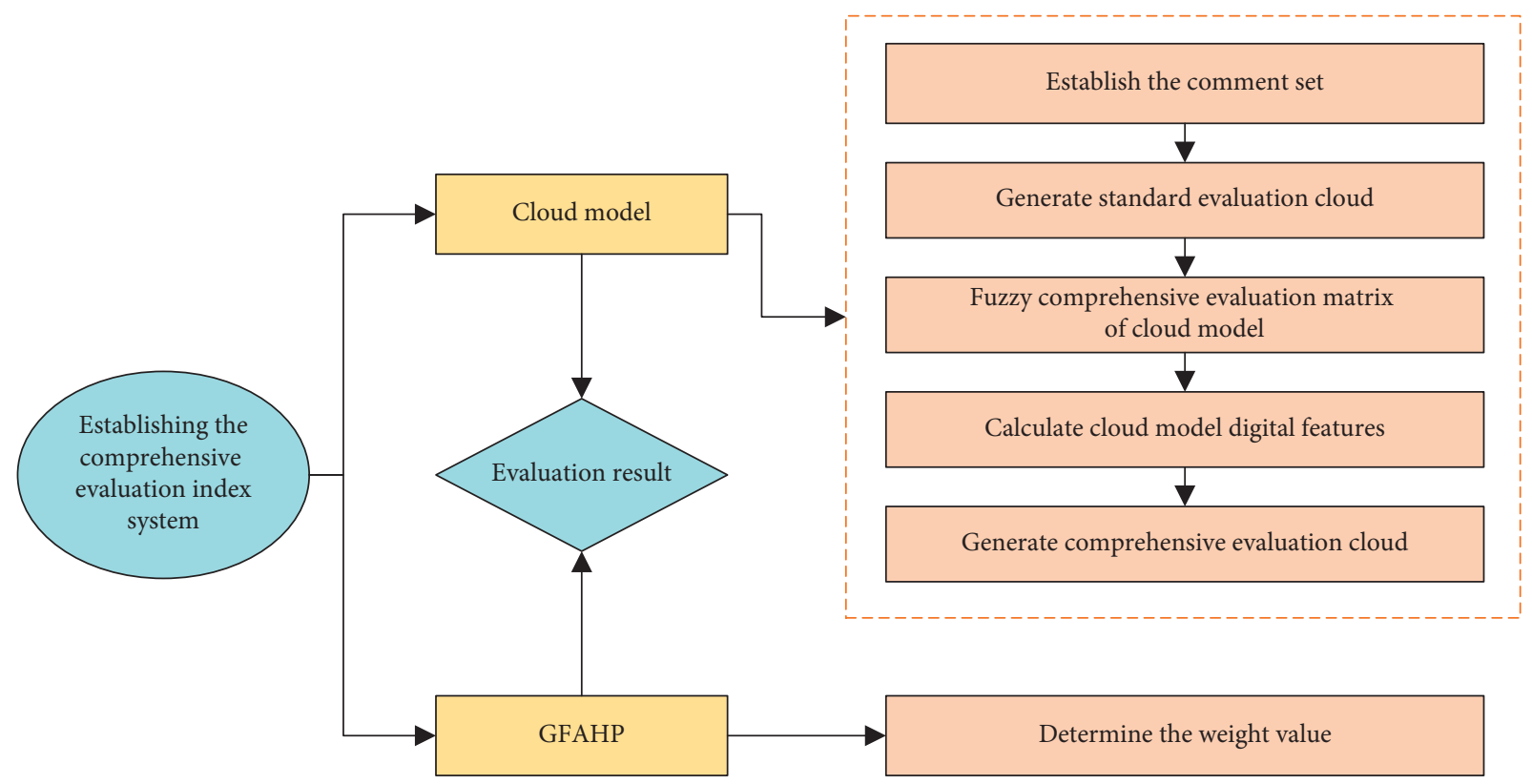

Figure 4: Flow chart of cloud model fuzzy comprehensive evaluation method.

TABLE 3: Calculation results of evaluation index weight.

\begin{tabular}{lcccc}
\hline Criterion layer & Weight & Indicator layer & Weight & Ultimate weight \\
\hline \multirow{4}{*}{0.1806} & $C 1$ & 0.3022 & 0.0546 \\
& & $C 2$ & 0.1539 & 0.0278 \\
& & $C 3$ & 0.1557 & 0.0281 \\
& & $C 4$ & 0.1848 & 0.0334 \\
& & $C 5$ & 0.2034 & 0.0367 \\
\hline \multirow{3}{*}{0.3021} & $C 6$ & 0.2397 & 0.0724 \\
& & $C 7$ & 0.1228 & 0.0371 \\
& & $C 8$ & 0.1390 & 0.0420 \\
& & $C 9$ & 0.3027 & 0.0915 \\
& & $C 10$ & 0.1958 & 0.0592 \\
\hline 33 & & $C 11$ & 0.1320 & 0.0683 \\
& \multirow{3}{*}{0.5173} & $C 12$ & 0.2923 & 0.1512 \\
& & $C 13$ & 0.2336 & 0.1209 \\
& & $C 14$ & 0.1887 & 0.0976 \\
\hline
\end{tabular}

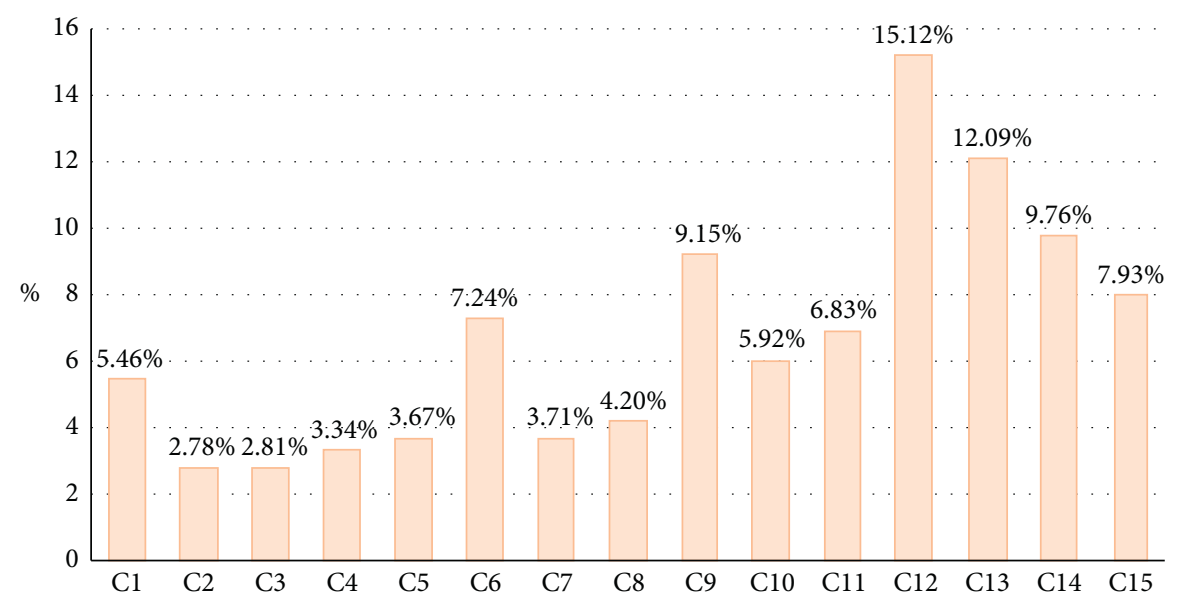

FigURE 5: Weight of comprehensive ability evaluation index of accounting applied talents. 
TABLE 4: Cloud model of comprehensive ability evaluation standard for accounting applied talents.

\begin{tabular}{lcr}
\hline Comment rate & Rating range & Digital characteristic \\
\hline Very good & $(8,10]$ & $(9,0.33,0.05)$ \\
Good & $(6,8]$ & $(7,0.33,0.05)$ \\
General & $(4,6]$ & $(5,0.33,0.05)$ \\
Poor & $(2,4]$ & $(3,0.33,0.05)$ \\
Very bad & $(0,2]$ & $(1,0.33,0.05)$ \\
\hline
\end{tabular}

judgment matrix given by the experts in this study has passed the one-time test, so the results are effective.

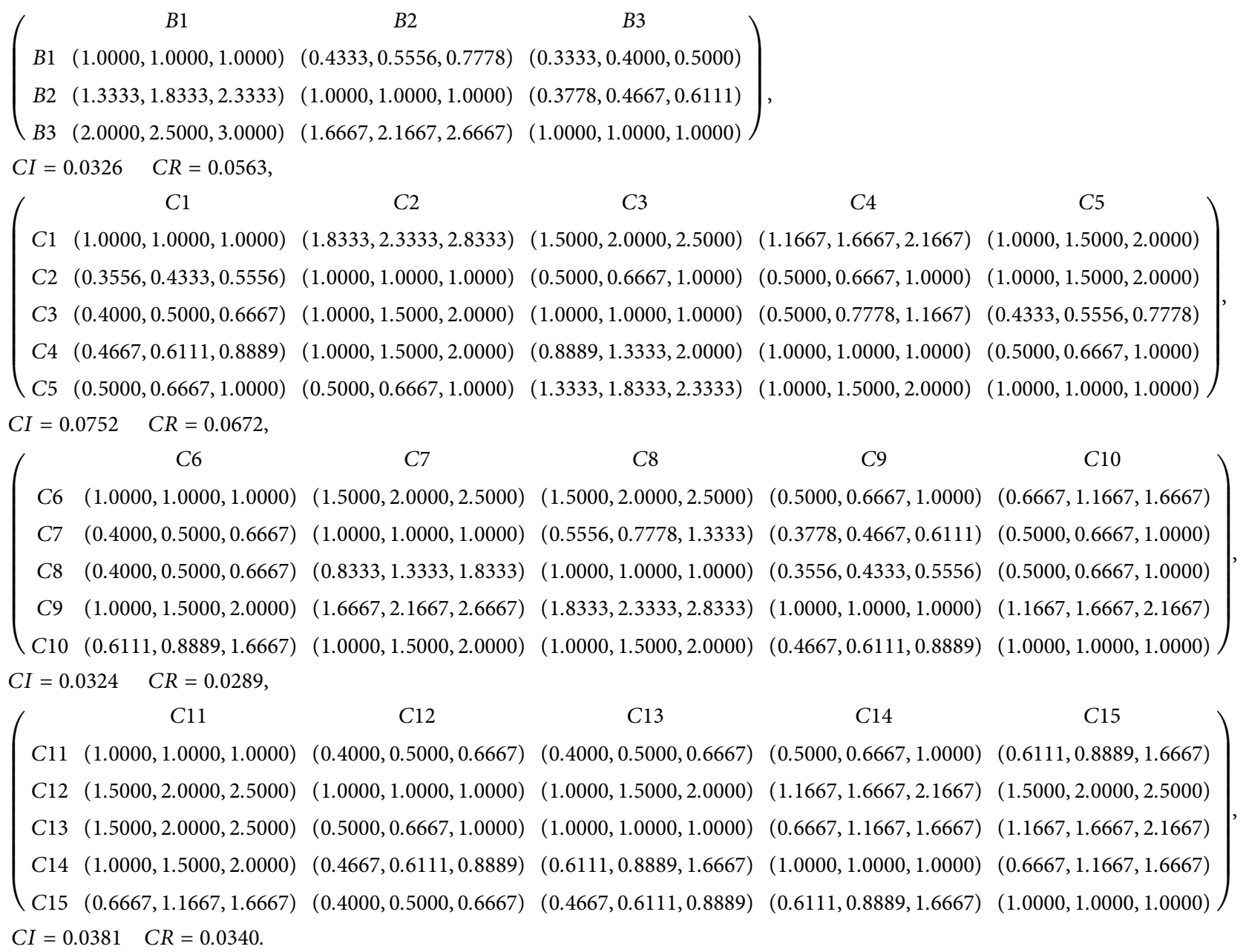

As can be seen from Table 3, moral level accounts for the highest proportion, followed by ability level. It shows that when training and selecting accounting applied talents, we should pay more attention to their ideology and moral character. Ability and knowledge can be improved through follow-up study, but thought determines one's basic quality. Besides, it can be seen from Figure 5 that the proportion of devotion to work and honesty are more than $10 \%$, followed by more important are team cooperation ability and compliance with the law, and the proportion of these two are close to $10 \%$, indicating that the cultivation of these abilities is very important in the cultivation of accounting applied talents.

5.2. Comprehensive Evaluation. This study aims to establish a relatively fair comprehensive ability evaluation model of accounting applied talents in the era of big data, so the evaluation object can be all students in accounting major, taking "class A" as an example. 


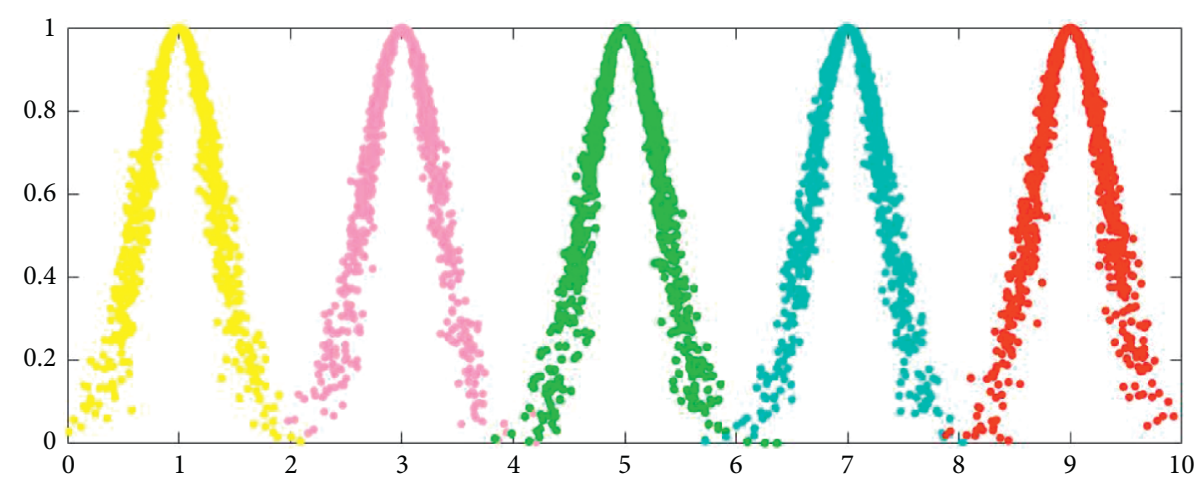

FIgURE 6: Cloud model diagram of comprehensive ability evaluation standard for accounting applied talents.

TABLE 5: Results of the expert's scoring for the classmate.

\begin{tabular}{|c|c|c|c|c|c|c|c|c|c|c|}
\hline \multirow{2}{*}{ Indexes } & \multicolumn{10}{|c|}{ Experts } \\
\hline & 1 & 2 & 3 & 4 & 5 & 6 & 7 & 8 & 9 & 10 \\
\hline$C 1$ & 7 & 5 & 8 & 7 & 8 & 7 & 8 & 6 & 7 & 8 \\
\hline$C 2$ & 3 & 3 & 4 & 6 & 5 & 5 & 6 & 4 & 3 & 4 \\
\hline$C 3$ & 5 & 4 & 7 & 6 & 6 & 6 & 7 & 6 & 7 & 5 \\
\hline$C 4$ & 8 & 5 & 6 & 7 & 7 & 7 & 7 & 8 & 7 & 7 \\
\hline C5 & 6 & 5 & 7 & 7 & 8 & 7 & 6 & 7 & 7 & 6 \\
\hline C6 & 5 & 4 & 7 & 7 & 7 & 6 & 6 & 6 & 7 & 4 \\
\hline$C 7$ & 5 & 5 & 9 & 8 & 9 & 7 & 7 & 7 & 8 & 6 \\
\hline C8 & 7 & 6 & 8 & 9 & 8 & 7 & 7 & 8 & 8 & 8 \\
\hline C9 & 8 & 6 & 8 & 8 & 7 & 7 & 8 & 7 & 8 & 8 \\
\hline$C 10$ & 8 & 6 & 8 & 9 & 8 & 7 & 8 & 7 & 8 & 7 \\
\hline$C 11$ & 9 & 9 & 7 & 8 & 8 & 7 & 9 & 9 & 7 & 9 \\
\hline$C 12$ & 9 & 6 & 7 & 8 & 8 & 6 & 6 & 7 & 7 & 7 \\
\hline$C 13$ & 8 & 7 & 9 & 9 & 8 & 7 & 7 & 8 & 8 & 6 \\
\hline$C 14$ & 9 & 6 & 8 & 8 & 9 & 8 & 8 & 8 & 8 & 9 \\
\hline C15 & 7 & 6 & 8 & 8 & 8 & 8 & 8 & 8 & 8 & 7 \\
\hline
\end{tabular}

TAвLE 6: Cloud digital characteristics of comprehensive ability evaluation index for accounting applied talents.

\begin{tabular}{lccr}
\hline Indexes & Ex & En & He \\
\hline$C_{1}$ & 7.1000 & 0.9024 & 0.4244 \\
$C_{2}$ & 4.3000 & 1.2032 & 0.5368 \\
$C_{3}$ & 5.9000 & 0.9275 & 0.3664 \\
$C_{4}$ & 6.9000 & 0.7019 & 0.6189 \\
$C_{5}$ & 6.6000 & 0.8523 & 0.3420 \\
$C_{6}$ & 5.9000 & 1.1781 & 0.4367 \\
$C_{7}$ & 7.1000 & 1.4037 & 0.7220 \\
$C_{8}$ & 7.6000 & 0.8523 & 0.3420 \\
$C_{9}$ & 7.5000 & 0.7520 & 0.3763 \\
$C_{10}$ & 7.6000 & 0.8523 & 0.3420 \\
$C_{11}$ & 8.2000 & 1.0027 & 0.2939 \\
$C_{12}$ & 7.1000 & 0.9275 & 0.3664 \\
$C_{13}$ & 7.7000 & 0.9525 & 0.2034 \\
$C_{14}$ & 8.1000 & 0.6768 & 0.6462 \\
$C_{15}$ & 7.6000 & 0.7019 & 0.4545 \\
\hline
\end{tabular}

Firstly, we establish a collection of comments. This study selects the set of comments as follows: $\mathrm{V}=$ \{very good, good, general, poor, very bad\}. Then, according to the formula, the numerical scoring interval of the comprehensive ability of accounting applied talents is transformed into the digital characteristic value of the cloud model. The calculation results are shown in Table 4 . To make the evaluation results more intuitive, 1000 cloud droplets are randomly generated by the forward cloud generator, and the standard evaluation cloud is drawn by MATLAB Software, as shown in Figure 6.

Secondly, we determine the fuzzy relation comprehensive evaluation matrix. Ten experts in the financial 


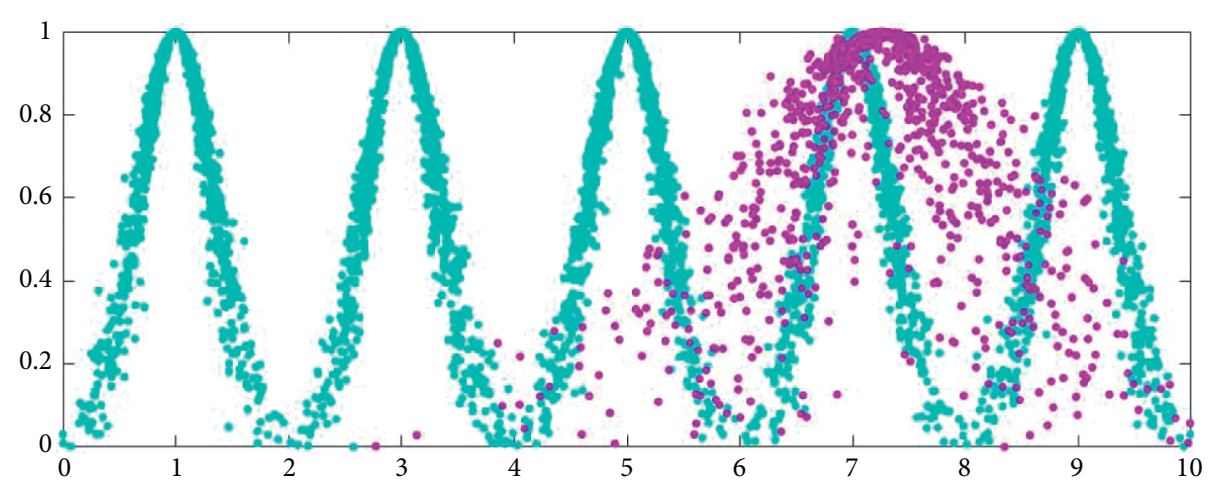

Figure 7: Comparison of standard cloud model and evaluation results cloud model results.

field are invited to score students in all aspects. The experts determine professional knowledge and learning ability according to class attendance, specific scores, and the number of subject studies. Besides, they determine moral level and other abilities according to the state of life and learning process and the evaluation of surrounding people. According to the above standards, the experts score results combined with their own experience, and the scoring results are shown in Table 5. Then, the cloud digital characteristics of the comprehensive ability evaluation index of accounting applied talents are calculated, as shown in Table 6 .

Finally, the evaluation value of class A's comprehensive ability is calculated according to the formula. The evaluation result of class A's comprehensive ability is represented by three cloud digital features, which are 7.2486, 0.9181, and 0.4082 , respectively. By drawing and comparing the standard cloud model and the evaluation result cloud model with MATLAB Software, we can see the comprehensive ability level of class A more clearly and intuitively. The blue curve in Figure 7 is the standard cloud model, and the purple curve is the cloud model of the comprehensive ability evaluation result of class A.

As can be seen from the schematic diagram of the evaluation results, the cloud image of the actual cloud model is mainly distributed between the "good" and "very good" regions, which is biased towards "good" and basically covers the "good" level of cloud model. Therefore, it can be considered that the accounting comprehensive ability of class A is at the "good" level. The numerical characteristics of entropy and hyperentropy in the comprehensive evaluation cloud are 0.9181 and 0.4082 , and the values are large. It is reflected in the cloud image that the cloud droplet distribution is relatively dispersed and the cloud image is wide, indicating that the fuzziness and discreteness of the comprehensive ability evaluation results are large and the data have certain randomness.

\section{Conclusions}

The comprehensive ability evaluation of accounting applied talents plays an important role in the training and employment of accounting applied talents, but the comprehensive ability evaluation of accounting applied talents is a systematic project with its own complexity. Therefore, this study constructs the evaluation index system from the three methods of knowledge level, ability level, and moral level. Then, the index weight is determined by the group fuzzy analytic hierarchy process, and the comprehensive ability of accounting applied talents is comprehensively evaluated by cloud model fuzzy comprehensive evaluation method. To a certain extent, it solves the uncertainty of talent comprehensive evaluation and overcomes the shortcomings of previous evaluation methods. Through case study, we find that the universities and enterprises should pay attention to moral level when training and selecting accounting applied talents. Then, based on the principle of people-oriented, job matching is carried out according to students' own advantages to achieve a win-win situation between candidates and interviewees. The construction and evaluation of this model scientifically quantify the comprehensive ability of accounting applied talents, which can help us determine the comprehensive quality of accounting talents objectively and fairly. It is not only beneficial to provide direction and suggestion for colleges and universities to cultivate accounting talents, but also can provide reference for enterprises to select accounting talents. However, due to the limitations of the evaluation object data, the construction of the index system is impossible to exhaust all aspects and the subjective preference of expert scoring and many other factors, and the universality of the evaluation model proposed in this study still needs continuous improvement so as to improve. In the future, we can construct the comprehensive ability evaluation 
index system of accounting applied talents from more aspects and use the weight calculation method combining qualitative and quantitative to determine the combination weight, so as to evaluate the comprehensive ability of accounting applied talents more scientifically.

\section{Appendix}

\section{$\mathbf{A}$}

Expert $1(\mathrm{E} 1)$

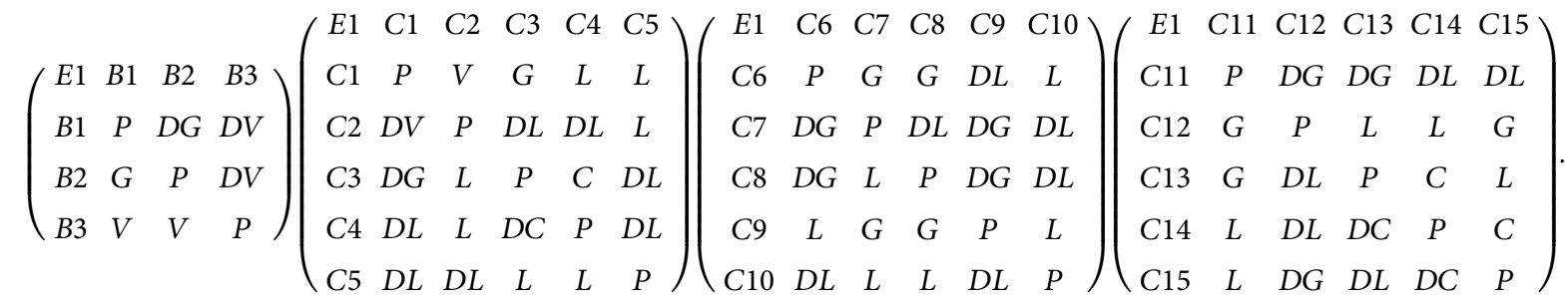

Expert 2 (E2)

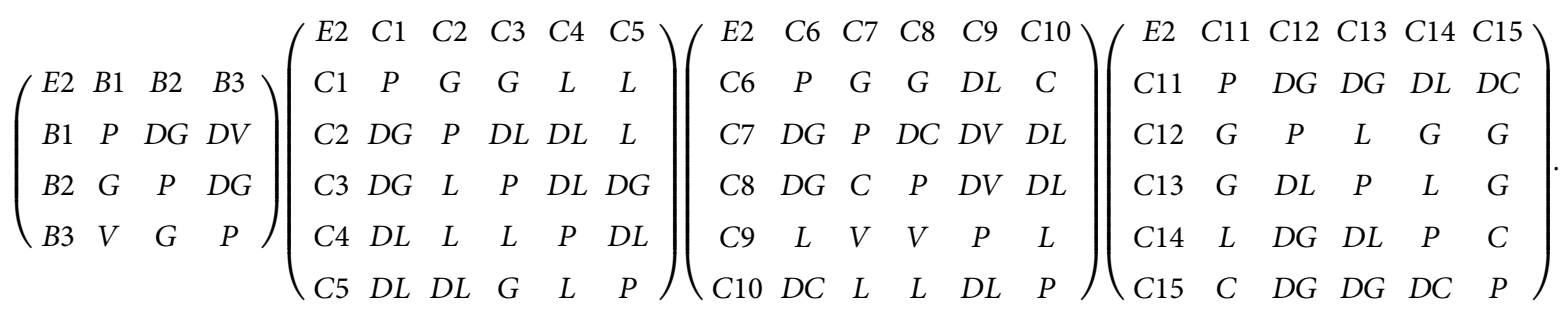

Expert 3 (E3)

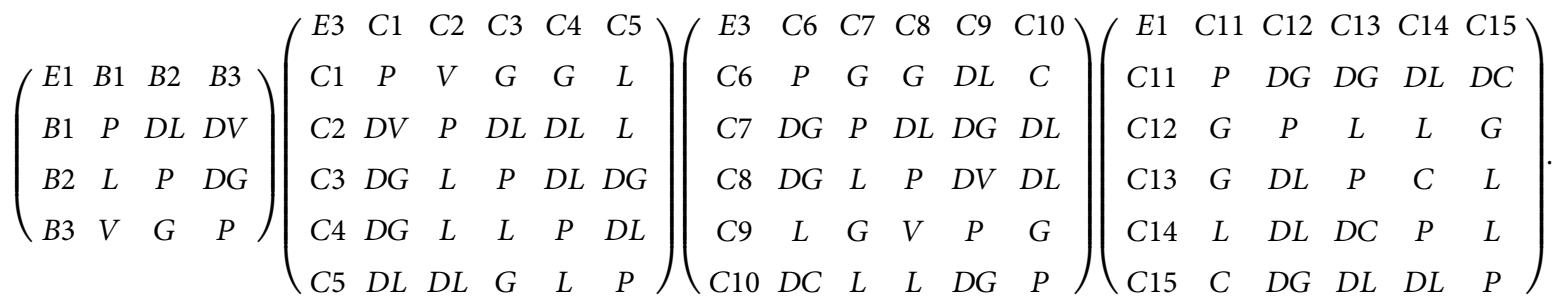

\section{Data Availability}

The data used to support the findings of this study are available from the corresponding author upon request.

\section{Conflicts of Interest}

The authors declare that they have no known conflicts of interests or personal relationships that could have appeared to influence the work reported in this study.

\section{References}

[1] Y. S. Fang and Y. X. Liu, "Comparative study on social demand-oriented talents training mode of modern accounting major," in Proceedings of the 5th International Conference on
Financial Innovation and Economic Development (ICFIED 2020), vol. 126, pp. 12-15, Sanya, China, January 2020.

[2] L. Jinming, "Study on innovative mode of accounting talents training based on "internet plus"” in Proceedings of the $3 \mathrm{rd}$ International Conference on Judicial, Administrative and Humanitarian Problems of State Structures and Economic Subjects (JAHP 2018), vol. 252, pp. 779-781, Domodedovo, Russia, April 2018.

[3] K. Kan, S. Agbodjo, and S. V. Gandja, "Accounting polycentricity in Africa: framing an 'accounting and development' research agenda," Critical Perspectives on Accounting, vol. 78, Article ID 102234, 2020.

[4] Y. Songqin and H. Jin, "How to build the management accounting talents training model based on diversified needs," in Proceedings of the 2019 4th International Conference on Social Sciences and Economic Development (ICSSED 2019), vol. 314, pp. 520-524, Wuhan, China, March 2019. 
[5] J. Hu, "Research on accounting talents training mode under the background of informatization," in Proceedings of the 4th International Conference on Education Management and Information Technology (ICEMIT 2018), pp. 827-830, Changchun, China, July 2018.

[6] C. Paisey and N. J. Paisey, "Talent management in academia: the effect of discipline and context on recruitment," Studies in Higher Education, vol. 43, no. 7, pp. 1196-1214, 2016.

[7] S. Nelson and L. Duxbury, "Breaking the mold: retention strategies for generations $\mathrm{X}$ and $\mathrm{Y}$ in a prototypical accounting firm," Human Resource Development Quarterly, vol. 32, no. 2, pp. 155-178, 2020.

[8] W. Zhou and J. Xia, "Research on the new training mode of accounting talents under the background of big data," in Proceedings of the 4th International Conference on Education Technology, Management and Humanities Science (ETMHS 2018), vol. 194, pp. 390-394, Taiyuan, China, February 2018.

[9] C. Paisey and N. J. Paisey, "Talent management in academia: the effect of discipline and context on recruitment," Studies in Higher Education, vol. 43, no. 7, pp. 1-19, 2016.

[10] D. E. . Clayson, "Student perception of instructors: the effect of age, gender and political leaning," Assessment \& Evaluation in Higher Education, vol. 45, no. 6, pp. 1-10, 2019.

[11] D. Clayson, "The student evaluation of teaching and likability: what the evaluations actually measure," Assessment \& Evaluation in Higher Education, no. 1, pp. 1-14, 2021.

[12] L. Alexander, "Sources of variance in end-of-course student evaluations," Assessment \& Evaluation in Higher Education, vol. 45, no. 1, pp. 44-53, 2020.

[13] R. Liu, "Training mode on innovative talents in universities," in Proceedings of the International Conference on Education, Economics and Social Science (ICEESS 2018), vol. 223, pp. 59-61, Singapore, October 2018.

[14] G. Song, "Reform and exploration of accounting professional practice teaching under the background of artificial intelligence," IOP Conference Series: Materials Science and Engineering, vol. 563, no. 5, Article ID 052005, 2019.

[15] Y. Zhang, "Model innovation and teaching effect evaluation of accounting teaching in higher vocational colleges in the era of big data," Educational Sciences: Theory and Practice, vol. 18, no. 6, pp. 3620-3627, 2018.

[16] Z. Zhu, J. Gao, and Y. Sheng, "Research on competency evaluation of accounting applied talents," in Proceedings of the 5th International Conference on Social Science and Higher Education (ICSSHE 2019), vol. 336, pp. 403-406, Xiamen, China, August 2019.

[17] L. Lan, "Evaluation on the innovation ability of talent through extenics evaluation method," International Conference on Computational Science and Engineering (ICCSE), vol. 81, pp. 249-256, 2017.

[18] K. Guo and L. Yang, "Research on evaluation of urban talent gathering ability-taking shenzhen city as an example," in Proceedings of the International Conference on Economic Management and Model Engineering (ICEMME 2019), vol. 12, pp. 628-632, Sanya, China, November 2019.

[19] H. He, H. Yan, and W. Liu, "Intelligent teaching ability of contemporary college talents based on BP neural network and fuzzy mathematical model," Journal of Intelligent and Fuzzy Systems, vol. 39, no. 9, pp. 1-11, 2020.

[20] F. Gao, "Establishment of college English teachers' teaching ability evaluation based on Clementine data mining," Journal of Intelligent and Fuzzy Systems, vol. 38, no. 6, pp. 1-9, 2020.
[21] F. Pawan Kumar and D. Claudio, "Implications of estimating confidence intervals on group fuzzy decision making scores," Expert Systems with Applications, vol. 65, no. dec, pp. 152-163, 2016.

[22] L. Coffey and D. Claudio, "In defense of group fuzzy AHP: a comparison of group fuzzy AHP and group AHP with confidence intervals," Expert Systems with Applications, vol. 178, Article ID 114970, 2021.

[23] L. Zhang, J. Chai, H. Xin, and Z. Zhao, "Evaluating the comprehensive benefit of hybrid energy system for ecological civilization construction in China," Journal of Cleaner Production, vol. 278, Article ID 123769, 2021.

[24] H.-G. Peng and J.-Q. Wang, “A multicriteria group decisionmaking method based on the normal cloud model with zadeh's Z -numbers," IEEE Transactions on Fuzzy Systems, vol. 26, no. 6, pp. 3246-3260, 2018.

[25] K. Cheng, Q. Fu, and J. Meng, "Analysis of the spatial variation and identification of factors affecting the water resources carrying capacity based on the cloud model," Water Resources Management: An International Journal, Published for the European Water Resources Association (EWRA), vol. 32, no. 8, pp. 1-15, 2018.

[26] F. Liu and Y. Wang, "A novel method of risk assessment based on improved AHP-Cloud model for freezing pipe fracture," Journal of Intelligent and Fuzzy Systems, vol. 41, no. 1, pp. 1-14, 2021. 